\title{
Osteosynthesis Results of Tibia Plateau Fractures at the Yalgado Ouedraogo University Hospital Center
}

\author{
S. C. Da, M. N. Dabiré, A. S. Korsaga, J. I. A. Ouédraogo, H. Kafando, S. Tinto, B. Sagnon, M. Tall \\ Department of Orthopedics-Traumatology, Yalgado Ouedraogo University Hospital Center, Ouagadougou, Burkina Faso \\ Email: songahirda@yahoo.fr
}

How to cite this paper: Da, S.C., Dabiré, M.N., Korsaga, A.S., Ouédraogo, J.I.A., Kafando, H., Tinto, S., Sagnon, B. and Tall, M. (2018) Osteosynthesis Results of Tibia Plateau Fractures at the Yalgado Ouedraogo University Hospital Center. Open Journal of Orthopedics, 8, 363-372.

https://doi.org/10.4236/ojo.2018.810039

Received: August 10, 2018

Accepted: October 9, 2018

Published: October 12, 2018

Copyright (c) 2018 by authors and Scientific Research Publishing Inc. This work is licensed under the Creative Commons Attribution International License (CC BY 4.0).

http://creativecommons.org/licenses/by/4.0/

\begin{abstract}
The sophistication of the implants allows the extension of the surgical indications for tibia plateau fractures. These fractures, which are often comminuted, are caused by a high velocity trauma, making treatment difficult. Objective: The aim of this study was to determine the indications for osteosynthesis of tibia plateau fractures in the orthopaedic-traumatology department of the Yalgado Ouédraogo University Hospital, in order to evaluate the results for their better management. Patients and Methods: it was a 5-year retrospective study of the records of patients with tibia plateau fracture operated and hospitalized in our department. The anatomical-clinical and therapeutic aspects collected from the complete files were analysed. A cortico-cancellous graft was performed in $67.4 \%$ of cases. The results were evaluated according to the criteria of Merle d'Aubigné and Mazas [1]. Road traffic accidents (97.4\%) were the predominant etiology, involving mainly motorcycles (97.8\%). Results: Spino-tuberository and uni-tuberository fractures were the most common. The average consolidation time was 12.5 weeks. One urinary infection, 3 superficial suppurations, 3 vicious calluses and 2 equipment dismantlings were the main complications. Our results were excellent and good in $91.3 \%$ and fair in $6.5 \%$. Osteosynthesis of tibial plateau fractures provides excellent results and remains the most appropriate procedure to treat these fractures. Conclusion: reduce the operating time, modernize the technical platform, will allow stable osteosynthesis and early functional rehabilitation to optimize their results.
\end{abstract}

\section{Keywords}

Fractures, Tibia Plateau, Osteosynthesis, Results

\section{Introduction}

Tibia plateau fractures are frequent and severe because of their joint character. 
They threaten the stability and mobility of the knee and can compromise walking and standing [2]. Consequently, they have been the subject of numerous studies throughout the world [3] [4] [5] [6]. The sophistication of implants allows the extension of their surgical indications. These fractures, often comminuted, are caused by high velocity trauma, making their treatment difficult. Their early and stable osteosynthesis will provide the best functional results after early rehabilitation.

In our country, very few studies, except Sawadogo's et al. [7]), have focused on the osteosynthesis of tibia plateau fractures, although these fractures rank third among pelvic limb injuries [8]. The objective of this study was to evaluate the results of osteosynthesis of tibial plateau fractures in the orthopaedics-traumatology department of the Yalgado Ouedraogo University Hospital Center (YO-UHC), in order to improve their therapeutic management.

\section{Patients and Methods}

We undertook a retrospective descriptive study in our department from January 2007 to December 2011. It concerned the files of patients operated and hospitalized for tibia plateau fractures.

Inclusion criteria: usable records of patients hospitalized for tibia plateau fracture, at least 15 years of age, were selected. Thus, out of a total of 2759 patients hospitalized during the study period, 150 patients had a tibia plateau fracture, representing a frequency of $5.43 \%$. But only 46 patients (59.8\%) operated, met our inclusion criteria.

Non-inclusion criteria: records of patients discharged against medical advice, incomplete records, records of patients hospitalized for other reasons, records not dating from the study period, 31 records (40.3\%) patients with tibia plateau fractures treated by orthopaedic methods, were excluded from the study.

Data were collected from patients' clinical records, surgeons' out patients records, surgical reports and medical certificates. The surgical therapeutic aspects of tibia plateau fractures were analyzed using Epi Info software version 3.5.1, Excel 2007 and SATA 10. A cortico-cortical bone graft was used in $67.4 \%$ of cases. The results were evaluated according to the criteria of Merle d'Aubigné and Mazas [1]. Patients were seen on external consultation at one month, two months, three months, six months, one year, one and a half years and two years.

The predominant etiology of these fractures was road traffic accidents (RTA) with 45 cases (97.8\%), followed by one case of aggression (2.2\%). Among the 45 RTA victims, motorcycles were the most involved (44 cases: 97.8\%) (Table 1).

The left pelvic limb was affected in 26 cases (56.5\%). Only two Cauchoix and Duparc type II open fractures were identified. According to Schatzker's classification, V-type bi-tuberosital fractures predominated (21 cases: 45.7\%) (Figure $1)$.

Table 2 shows the distribution of patients according to Schatzker's classification.

The different associated fractures are summarized in Table 3. 
Table 1. Distribution of patients by type of collision $(n=45)$.

\begin{tabular}{ccc}
\hline Type of collision & Number & (\%) \\
\hline Motorcycle only & 8 & 17.8 \\
Motorcycle - animal & 3 & 6.7 \\
Motorcycle - cart & 1 & 2.2 \\
Motorcycle - Motorcycle & 12 & 26.7 \\
Motorcycle - pedestrian & 5 & 11.1 \\
Motorcycle - bicycle & 9 & 20.0 \\
Bicycle - bicycle & 1 & 2.2 \\
Motorcycle - car & 6 & 13.3 \\
Total & 45 & 100 \\
\hline
\end{tabular}

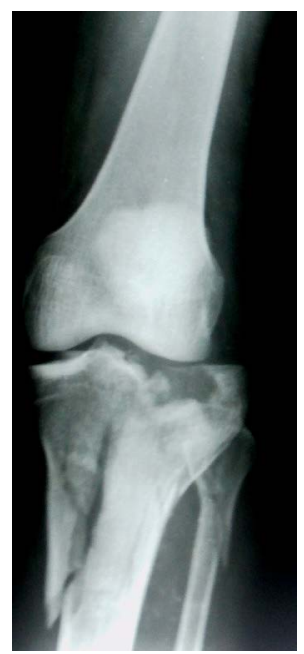

Figure 1. Frontal radiographic image showing a Schatzker V-type comminuted bi-tuberository fracture in a 30-year-old woman, following a road traffic accident.

Table 2. Distribution of tibial plateau fractures according to Schatzker [9].

\begin{tabular}{cccccccc}
\hline & Type I & Type II & Type III & Type IV & Type V & Type VI & Total \\
\hline Number & 5 & 9 & 6 & 3 & 21 & 2 & 46 \\
$\%$ & 10.9 & 19.6 & 13 & 6.5 & 45.7 & 4.3 & 100 \\
\hline
\end{tabular}

Table 3. Association of fractures from other localization.

\begin{tabular}{ccc}
\hline Localization & & Number \\
\hline Thoracic limb & Humeral diaphysis & 1 \\
& Olecranon & 1 \\
& Forearm & 2 \\
& Femoral diaphysis & 2
\end{tabular}


Continued

\begin{tabular}{ccc}
\hline & Fibular head & 11 \\
Pelvic limb & Tibial diaphysis & 4 \\
& Fibular diaphysis & 3 \\
Total & Lateral malleolus & 2 \\
& & $\mathbf{2 3}$ \\
\hline
\end{tabular}

The two open fractures were trimmed between 6 and 24 hours after the trauma. Osteosynthesis was performed in 30 women (65.2\%) and 16 men (34.8\%), for a sex-ratio of 0.5. A tourniquet was used during osteosynthesis in 35 patients (76.1\%). Six patients had received iso-group, iso Rhesus blood transfusion during osteosynthesis. A homolateral iliac crest cortico-cancellous graft was performed in 31 patients (67.4\%) to fill a metaphyseal defect of the tibia plateau reduced by raising (Figure 2(a), and Figure 2(b)).

The average operating time for osteosynthesis was 24.5 days (6 - 58). It is summarized in Figure 3.

Fourteen patients (30.4\%) were operated within 20 - 30 days. The age distribution of the different types of osteosynthesis implants is shown in Figure 4 (n = 56). NB: At least two types of osteosynthesis implants were used in the same patient. The T-screw plate was the most used (30 cases: $53.6 \%$ ), especially in the 30 - 39 age group (26.8\%) (Figure 4 and Figure 5).

The T-screwed plate was the most commonly used (15 cases) in patients aged 30 to 39 years.

\section{Results}

The average length of hospitalization was 16.5 days (0 - 90). It was 17.5 days for women and 15.8 days for men. Hospital stays of 20 to 29 days predominated (30.4\%). Figure 6 shows the distribution of patients hospital stay.

The average post-operative follow-up was 15 months ( 6 - 30). The average consolidation time in patients was 8.3 weeks (6 - 16). Forty-one patients (89.1\%) had consolidated their fractures between 6 and 8 weeks and the remaining 5 $(10.9 \%)$ at 8 weeks. The progression of osteosynthesis was favourable in 35 patients (76.1\%); and the other 11 patients (23.9\%) had 8 types of complications (Figure 7).

The results were satisfactory (good and excellent) in 42 cases (91.3\%). Figure 8 illustrates the distribution of functional results. Functional results were excellent in $28.6 \%$ and good in $58.4 \%$.

Osteosynthesis had produced excellent and good results in 42 cases (91.3\%). According to Schatzker's classification, 13 types V fractures (28.3\%) had given satisfactory results (Figure 9).

The excellent and good results were obtained mainly in Schatzker's Type II (19.4\%) and V (28.3\%) fractures. 


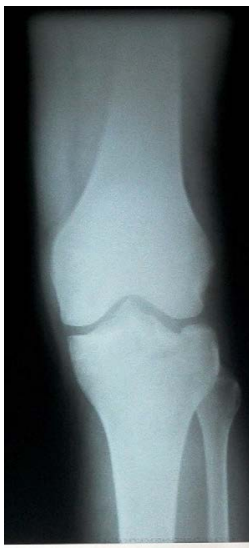

(a)

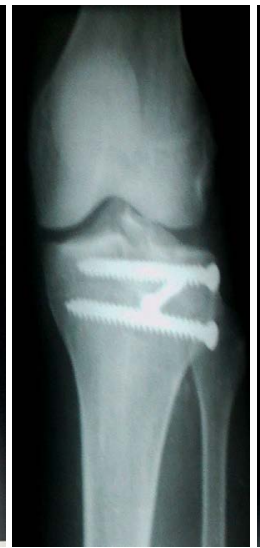

(b)

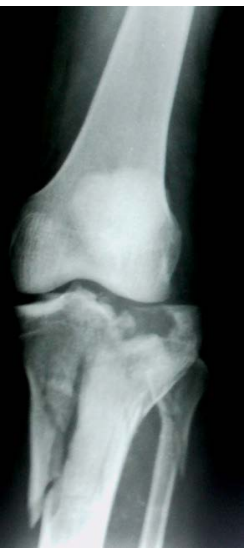

(c)

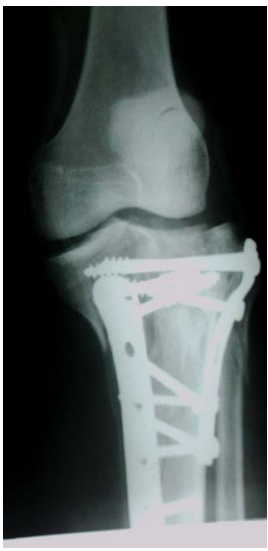

(d)

Figure 2. (a) Initial radiographic image showing a uni-tuberosciary fracture with depression of the Schatzker type III lateral tibia plateau in a 28-year-old male; (b) Post-operative radiographic image of a screwing impacted with filling of the defect by an ipsi-lateral iliac crest cortico-soft graft; (c) Frontal radiographic image showing a Schatzker V-type comminuted bituberository fracture in a 30-year-old woman, following a road traffic accident; (d) Post-operative radiographic image of osteosynthesis with two $\mathrm{L}$ and $\mathrm{T}$ plates and a cortico spongy graft to fill the bone defect of the 30 -year-old patient's lateral plateau.

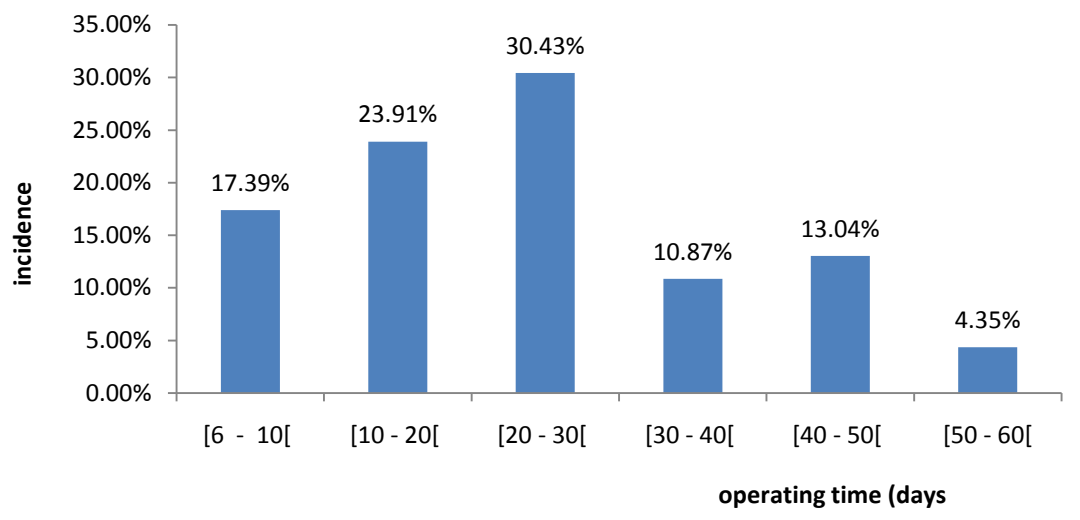

Figure 3. Distribution of patients by operating time.

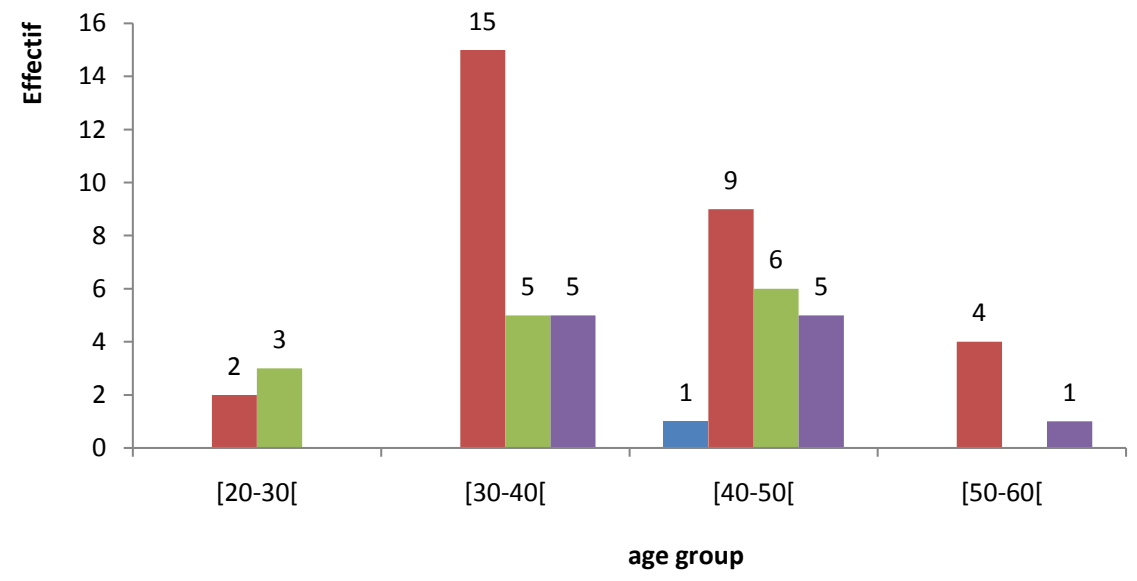

Figure 4. Type of osteosynthesis implants used depending on age group. Kirschner wires (blue), T-plate (red), L-plate (green), percutaneous screw (purple). 


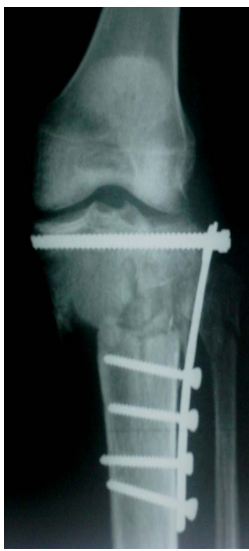

(a)

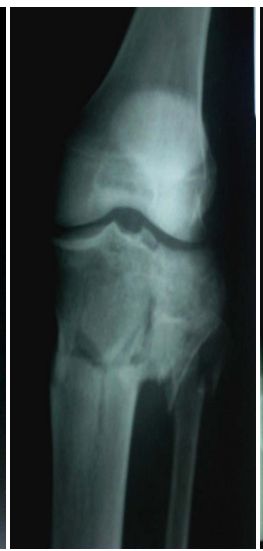

(b)

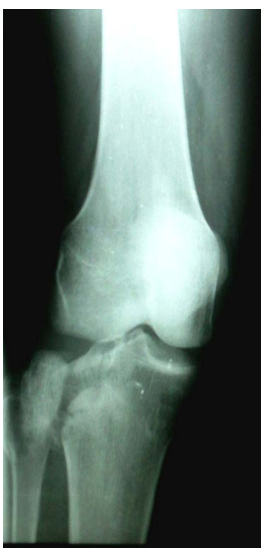

(c)

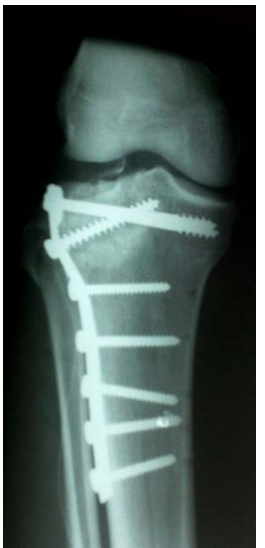

(d)

Figure 5. (a) Initial radiographic image of the face, showing a Schatzker type II mixed lateral uni-tuberosity fracture in a 39-year-old woman; (b) Post-operative radiographic image of the face showing osteosynthesis by screwed T-plate and cortico-soft graft to fill the bone defect after reduction of the depression; (c) Initial frontal radiographic image showing a comminuted bi-tuberository fracture associated with a Schatzker type VI fracture of the proximal tibial metaphysis with diaphysis cleft in a 40-year-old Woman; (d) Post-operative radiographic image of a 48-year-old woman showing osteosynthesis by a screwed T-shaped plate.

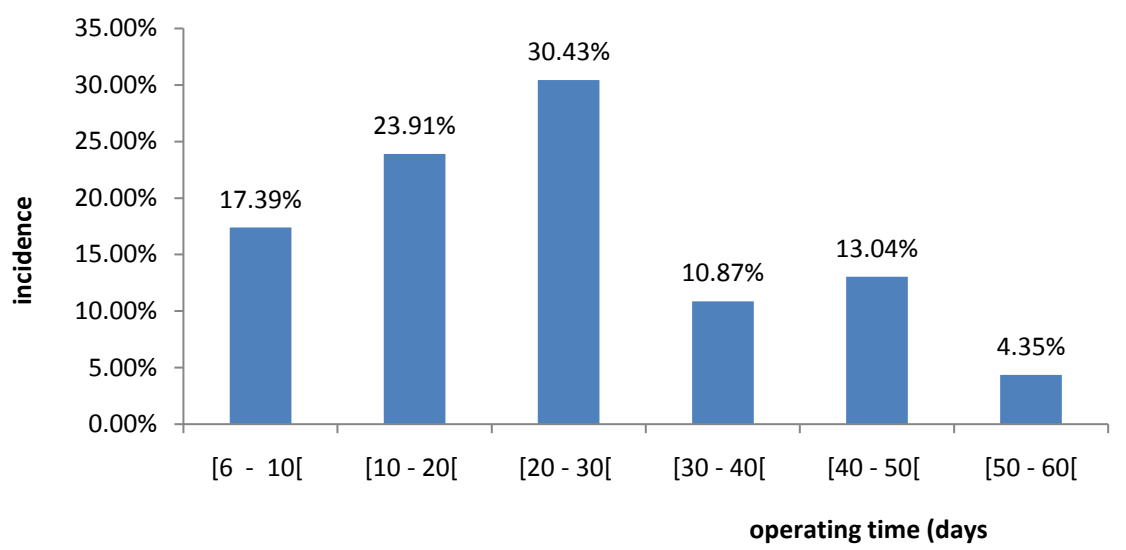

Figure 6. Distribution of patients according to hospital stay.

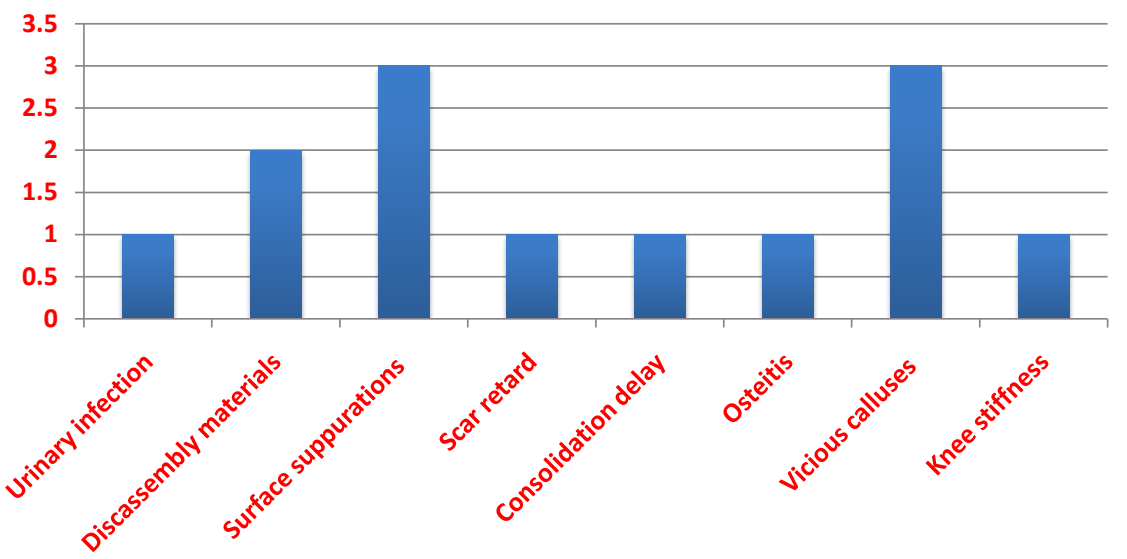

Figure 7. Distribution of 8 types of complications in 11 patients. 


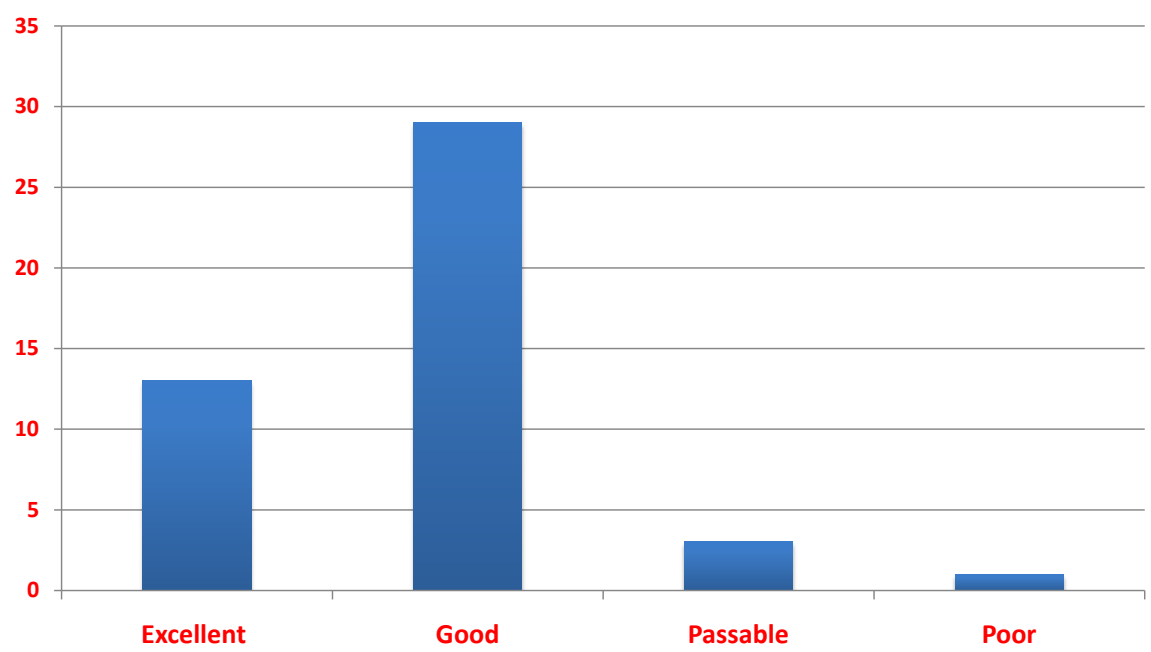

Figure 8. Functional outcomes of operated patients.

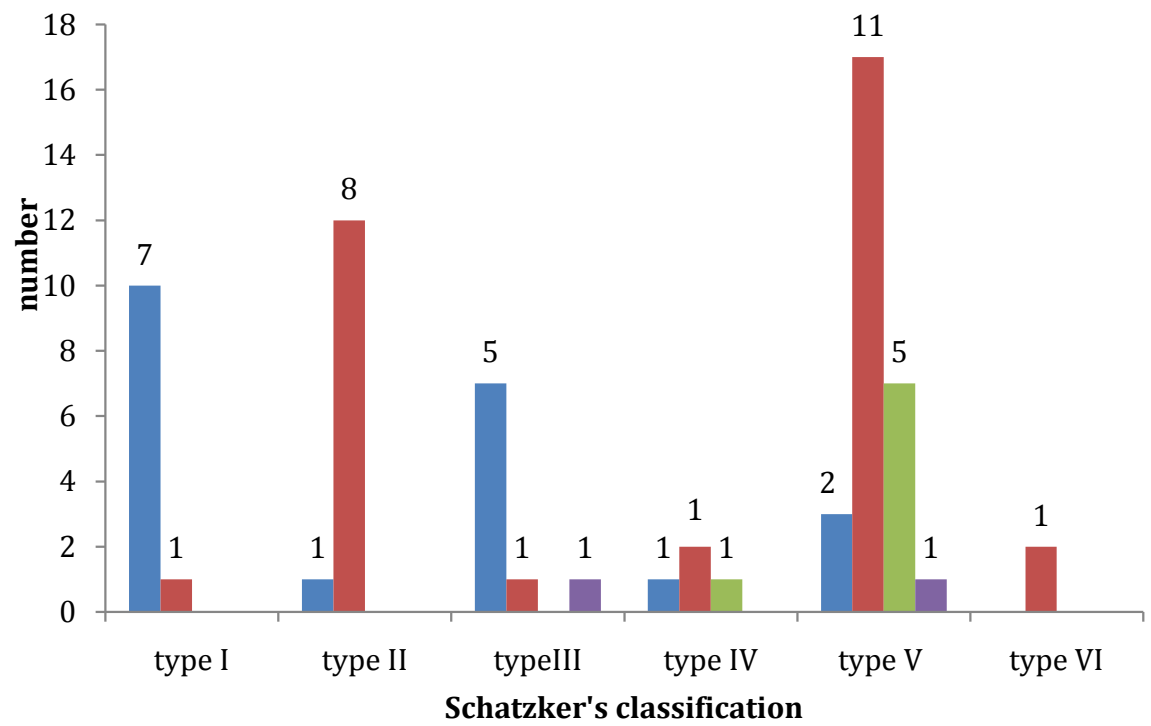

Figure 9. Functional results of osteosynthesis of tibia plateau fractures according to Schatzker classification. Excellent (blue), good (red), fair (green), poor (purple).

\section{Discussion}

The retrospective nature of this hospital study does not reflect the real situation of the tibia plateau fractures of our country. In addition, certain data relating to the post-operative evolution were obtained by telephone call. The high costs of surgical treatment, the preference for traditional treatment for some patients, and even the fear of surgery, were obstacles to osteosynthesis.

Despite these constraints, the osteosynthesis of 46 tibia plateau fractures was performed in our department in 5 years. Like Sawadogo et al. [7] (95\%), Koulali et al. [5] (82\%), RTA were the predominant etiology (97.8\%) of these fractures, mainly involving two motorized wheels (63\%). The left pelvic limb was the most affected (56.5\%). According to Schatzker's classification, type V fractures predominated (45.7\%). Osteosynthesis was performed in 30 women (65.2\%) and 16 
men $(34.8 \%)$, for a sex-ratio of 0.5 . The overall rate of osteosynthesis in our series was (59.7\%). This rate is close to those of Honkonen and Järvinen [4], and Koulali et al. [5] with $58 \%$ and $68 \%$ respectively.

Fourteen of our patients (34.4\%) were operated within 20 - 30 days. This delay is longer than that noted by Hachimi et al. [3] with a delay of 3 - 4 days. The insufficiency of our technical platform, the insufficient number of orthopaedic surgeons and the low purchasing power of our patients are the main reasons. Open hearth osteosynthesis was the only surgical method undertaken in our series. The T-shaped screw plate was the most used (65.2\%), especially in the 30 39 age group (32.6\%). Our attitude is consistent with those of Sawadogo et al. [7], but different from those of Koulali et al. [5] with a rate of 50\% and Le Huec [10] $40 \%$ with open hearth osteosynthesis. The inadequacy of our technical platform does not favour osteosynthesis with a closed focus. According to Sie and Lamblin [11], Schatzker V and VI fractures can be treated by minimally internal osteosynthesis and external neutralization fixation. Koulali et al. [5] also noted a high frequency of use of screwed plates; however, Le Huec [10] found no difference in use of osteosynthesis equipment. The frequent use of the screwed plate could be explained by the stability and solidity of the fixing it offers. A bone graft was necessary in $67.4 \%$ of cases during osteosynthesis in order to fill the metaphyseal defect created by the raising of the sunken plateau. It was a cortico-cancellous graft taken from the homolateral iliac crest. This attitude is consistent with the literature as noted by Koulali et al. [5] and Le Huec [10]. The average length of hospitalization was 16.5 days $(0-90)$. This differs from Sawadogo et al. [7] with a shorter average hospital stay (11.5 days). The shorter hospital stay of Sawadogo et al. [7] could be explained by the regional nature of his study. The average consolidation time for patients was 8.3 weeks $(6-16)$. Forty-one patients $(89.1 \%)$ consolidated in 6 - 8 weeks. Our consolidation times are superimposed on those of Koulali et al. [5] with 6 - 8 weeks for surgical treatment. Forty-one patients $(89.1 \%)$ had consolidated their fractures between 6 and 8 weeks and the remaining $5(10.9 \%)$ at 8 weeks. The evolution of osteosynthesis was favourable in 35 patients $(76.1 \%)$ and the 11 others $(23.9 \%)$ had complications. This rate is close to that of Sawadogo et al. [7], with $91 \%$. One case of urinary tract infection was noted in our series. Early locoregional complications were characterized by 2 disassemblies of the synthetic material (4.3\%), 3 superficial suppurations (6.5\%) without identified germ and 1 delayed healing (2.2\%). One case of osteitis $(2.2 \%)$ was the secondary complication in our series. Late locoregional complications included 1 consolidation delay (2.2\%). 3 vicious calluses (6.5\%) and 2 knee stiffnesses (4.3\%). The complications of osteosynthesis in our series are different from those reported by other authors. Sawadogo et al. [7] noted 1 case of fracture suppuration, 2 cases of vicious callus, 3 cases of joint stiffness and 1 case of osteoarthritis. The same is true in the series of Koulali et al. [5] with cases of deep sepsis, pseudarthrosis, vicious callus and joint stiffness. Despite these differences, our functional results are not different from those of the literature since vicious callus and joint stiffness are the most common. The func- 
tional results of our series were satisfactory in $87 \%$ (excellent and good), fair in $10.4 \%$ and poor in $2.6 \%$. These results show that early osteosynthesis of tibial plateau fractures offers excellent results. Our rates are comparable to those of Koulali et al. [5] with 67\% good and very good results, Sawadogo et al. [7] with Duparc and Filipe [12] with 79\%. Le Huec [10] with 88\%. Kasse NA et al. [13] obtained excellent and good results (12 cases out of a total of 14) in the treatment of complex tibia plateau fractures (Schatzker types V and VI). We don't have any experience in the osteosynthesis of tibia plateau fractures by Ilizarov external fixator. with $79 \%$. Surgical treatment was also better in the Koulali series [5] with $70 \%$ good results against $50 \%$ for orthopaedic treatment.

\section{Conclusion}

Tibial plateau fractures are mainly the result of road traffic accidents, often involving motorized two-wheeled vehicles. The violence of the shock mainly causes Schatzker V-type fractures (21 cases: $45.7 \%)$. Secondary osteosynthesis was the treatment of choice. T- and L-screwed plates have been the most used; this is related to the stability they offer. Vicious callus was one of the most frequent late complications occurring mainly as a result of insufficient reduction or favoured by loosely rigid osteosynthesis. Despite the long operating time, functional results were satisfactory in $87 \%$. Hence the need to improve our results through modernising our technical platform, which will enable early and stable osteosynthesis for early rehabilitation, guaranteeing better functional results.

\section{Conflicts of Interest}

The authors declare no conflicts of interest regarding the publication of this paper.

\section{References}

[1] Masses, Y. and Mazas, F. (1977) devenir à long terme des fractures des plateaux tibiaux. Revue de Chirurgie Orthopédique et Traumatologique, 63, 203.

[2] Huten, D., Duparc, J. and Cavagna, R. (1990) Fractures des plateaux tibiaux de l'adulte [14-082-A-10]. Ajout d'une étoile "en dur" pour les articles de JRDIA

[3] Hachimi, Kh., Bekkali, Y., Fnini, S., Rafai, M., Garch, A., Ouarab, M. Largab, A. and Trafeh, M. (2006) Traitement des fractures des plateaux tibiaux par vissage percutané service de traumatologie-orthopédie, CHU Ibn Rochd. Revue Marocaine de Chirurgie Orthopédique et Traumatologique, 26, 20-21.

[4] Honkonen, S.E. and Järvinen, M.J. (1992) Classification of Fractures of the Tibial Condyles. The Journal of Bone and Joint Surgery, 74b, 840-847. https://doi.org/10.1302/0301-620X.74B6.1447244

[5] Koulali, K.I., Rafai, M., Cohen, D., Fnini, S., Largab, A., Ouarab, M. and Trafeh, M. (2003) Fractures des plateaux tibiaux: à propos de 100 cas. Revue Marocaine de Chirurgie Orthopédique et Traumatologique, 18, 14-21.

[6] Laporte, J.D. (2000) Epidémiologie des fractures du plateau tibial. Doc Web.

[7] Sawadogo, M., Dakouré, P., Tall, M., Kafando, H., Ouédraogo, S. and Da, S.C. (2013) 
Fractures des plateaux tibiaux au Centre Hospitalier Régional de Ouahigouya (Burkina Faso): résultats du traitement chirurgical. Orthopedics Emergency of Africa, 2, 19-21.

[8] Da, S.C., Ouedraogo, S., Dieme, C., Kafando, H., Zan, A., Nacoulma, S.I. and Ouedraogo, R.K. (2008) Fracture de membres aux urgences traumatologiques de Ouagadougou (Burkina Faso). Journal des Sciences, 8, 1-9.

[9] Trojani, Ch., Jacquot, L., Aït Si Selmi, T. and Neyret, P.H. (2003) Les fractures récentes des plateaux tibiaux de l'adulte: physiopathologie, diagnostic, classifications et traitement: Maîtrise Orthopédique $\mathrm{n}^{\circ} 127$.

[10] Le Huec, J.C. (1996) fractures articulaires récentes de l'extrémité supérieure du tibia. Conférence d'enseignement. Cahiers d'Enseignement de la SOFCOT, n55, 97-117.

[11] Sie Essoh, J.B. and Lambin, Y. (2016) Fractures des plateaux tibiaux à haute vélocité: évaluation et traitement. [High Energy Tibial Plateau Fractures: Evaluation and treatment.] African Journal of Orthopeadics and Trauma, 1, 95-101.

[12] Duparc, J. and Filipe, G. (1975) Fractures spino-tubérositaires. Revue de Chirurgie Orthopédique et Traumatologique, 61, 705-716.

[13] Kasse, N.A., Soulama, M., Diao, S., Diallo, M., Thiam, B. and Sy, M.H. (2016) Traitement des fractures complexes des plateaux tibiaux par la méthode d'llizarov. African Journal of Orthopeadics and Trauma, 1, 120-125. 